Original paper

\title{
Association of TNF- $\alpha$ and CCL5 with response to interferon-based therapy in patients with HCV 1 genotype
}

\author{
Dzmitry Danilau', Dzmitry Litvinchuk', Nikita Solovey¹, Olga Krasko², Igor Karpov¹ \\ 'Belarusian State Medical University, Minsk, Belarus \\ ${ }^{2}$ The United Institute of Informatics Problems of the National Academy of Sciences of Belarus, Minsk, Belarus
}

\begin{abstract}
Aim of the study: To evaluate the role of potential genetic predictors -308G/A TNF- $\alpha$ and $-403 \mathrm{G} / \mathrm{A}$ CCL5 in treatment for HCV 1 genotype.

Material and methods: Treatment results of 130 patients with chronic hepatitis $C 1$ genotype according to different genotypes of IL28B, CCL5, and TNF- $\alpha$ were analysed using multiple logistic regression.

Results: IL28B genotypes CC/CT/TT were found in $27(20.8 \%), 74$ (56.9\%), and 29 (22.3\%) patients. Genotypes GG/GA/AA of -308G/A TNF- $\alpha$ were revealed in $98(75.4 \%)$, $30(23.1 \%)$, and 2 (1.5\%) patients. Genotypes GG/GA/AA of $-403 \mathrm{G} / \mathrm{A} \mathrm{CCL5}$ were revealed in $86(66.2 \%)$, $39(30 \%)$, and $5(3.8 \%)$ patients, respectively. The previously known effect of IL28B was observed. IL28B TT genotype decreased end of treatment response (EOTR) rates by a factor of 29.0 (95\% Cl: 6.4-183). The combination of CCL5 GG and IL28B CT genotypes increased the risk of failure to achieve EOTR by a factor of 28.5 (95\% Cl: 7.2-160). Genotypes GA and AA of TNF- $\alpha(-308) \mathrm{G} / \mathrm{A} \mathrm{SNP}$ increased the risk of relapse in patients who achieved EOTR (OR $=9.4 ; 95 \% \mathrm{Cl}: 2.4-48)$. Conclusions: Practitioners may benefit from using these predictors when considering indications for the antiviral therapy and deciding on the treatment regimen.
\end{abstract}

Key words: SNP, peginterferon alfa, IL28B, TNF- $\alpha$, CCL5.

Address for correspondence

Dr. Dzmitry Danilau, Belarusian State Medical University, Dzerzhinsky Ave. 83, 220016 Minsk, Belarus, phone: +375293770203, fax: +375173341443, e-mail: d.danff@gmail.com

\section{Introduction}

Currently, more than 180 million people worldwide are infected with chronic hepatitis C [1]. Hepatitis C virus persists in $55-85 \%$ of cases of acute hepatitis C. Persistence of infection causes progredient liver tissue damage and a deterioration in liver function. Age, male sex, and duration of chronic infection are associated with disease in progression rates [2]. Moreover, higher duration of chronic disease results in an increased risk of cirrhosis formation (up to $20-30 \%$ in patients after 20 years) $[3,4]$. Hepatitis $C$ virus and human immunodeficiency virus coinfection (HCV/HIV) dramatically increases cirrhosis incidence rate and risk of further liver function decompensation [5]. The overall incidence of liver failure and hepatocellular carcinoma (HCC) in patients with cirrhosis is around $2-5 \%$ and $1-4 \%$ per year, respectively [6]. HCV-infection and related sequelae lead to more than 500,000 deaths annually [7].

Hepatitis $\mathrm{C}$ virus has seven distinct genotypes (numbered 1 to 7 ) and up to 67 subtypes (indicated by the letter following the genotype) [8]. All genotypes have specific geographic distribution and genetic diversity, except genotype 5 , which has only one subtype $-5 a$. Reports on novel genotype 7 from Central Africa emerged in 2015 [9].

The most widespread genotype is genotype 1 (subtype $1 \mathrm{~b}$ ), which comprises up to $46 \%$ or more than 80 million patients with chronic hepatitis C. The HCV genotype 3 prevalence rate among patients with chronic 
hepatitis $\mathrm{C}$ is around $30 \%$, and genotypes 2,4 , and 6 are causative of around $22.8 \%$ of total chronic hepatitis C cases. The prevalence of genotype 5 is less than 1\% [1]. The prevalence of genotype 7 remains unclear.

The type and duration of antiviral treatment for $\mathrm{HCV}$ infection mainly depend on virus genotype. It is true not only for interferon-based therapies but also for interferon-free schemes [10]. Simultaneous infection with several HCV genotypes is possible and is called mixed infection. A possible cause of the mixed genotype $\mathrm{HCV}$-infection is repeated exposure to a source of infection, which is the attribute of intravenous drug users and patients with haemophilia [11]. Selection of $\mathrm{HCV}$ genetic variant with moderate drug resistance in mixed infection may be one of mechanisms of viral escape in interferon-based therapy [12].

Globally in the next 20 years the rates of HCV-related advanced liver diseases and direct healthcare costs will increase, despite the reduction in chronic hepatitis $\mathrm{C}$ prevalence [13].

Interferon-based treatment options provide rates of SVR (sustained virological response) at 36-63\% [14, 15] (or, 482-602 per 1000 treated patients [16]).

PEG-IFN and ribavirin are still being used in the countries with low and lower middle income, and where direct acting antivirals are not available (or are not approved). Such therapy option is usually used in the treatment of children and adolescents. Due to the high rate of the severe side effects in patients with interferon-based treatment and relatively low levels of SVR, it is important to evaluate the chances for a positive outcome before starting antiviral treatment.

Over the past decade, several genome-wide association studies (Ge et al., Tanaka et al.) discovered two single-nucleotide polymorphisms (SNPs, rs12979860C/T, and $\mathrm{rs} 8099917 \mathrm{~T} / \mathrm{G}$ ) near the IL28B gene on chromosome 19. These SNPs demonstrate the ability to modify the outcome of antiviral treatment for chronic hepatitis $C$ with PEG-IFN and ribavirin $[18,19]$. In patients with rs12979860CC genotype (or IL28B CC) and HCV genotype 1 treatment for chronic hepatitis $\mathrm{C}$ with PEGIFN and ribavirin has a success rate of $80 \%$, but with SNP IL28B TT this therapy succeeds only in $25 \%$ of patients. IL28B CT shows an intermediate effect on the treatment outcome; about $20-40 \%$ of patients with chronic hepatitis $\mathrm{C} 1$ genotype reach sustained virological response [19]. A similar effect of $r 12979860 \mathrm{C}>\mathrm{T}$ on the treatment response is observed in patients with HCV genotype 2 and 3 [20].

This SNP IL28B rs12979860 C>T also affects the natural course and therapy outcome in patients with HCV recurrence after liver transplantation. In the case of a liver graft reinfection of the donor's IL28B genotype but not the recipient's one has a higher influence on the disease course and treatment outcome. Although IL28B genotype CC predicts high alanine aminotransferase level and viral load in liver graft it also increases sustained virological response rates to IFN-based treatment [21].

There are still no new host genetic factors with an IL28B-like manner and potency of prediction. Nevertheless, some non-IL28B genetic polymorphisms tend to interfere with pathophysiological mechanisms common to several diseases (including HCV infection).

Chemokines as a protein family play a significant role in immunological and inflammatory processes. Chemokine CCL5 or RANTES (regulated on activation, normal $\mathrm{T}$ cell expressed and secreted) acts as a chemoattractant for monocytes, $\mathrm{T}$ helpers, and eosinophils. CCL5 activates hepatic stellate cells and enhances migration of immune cells in chronic hepatitis $\mathrm{C}$ including Th1, which is crucial for immune control over HCV [22]. Endothelium cells of the hepatic portal system express CCR5-associated chemokines on their surface. In the course of chronic hepatitis $\mathrm{C}$, the amount of expressed chemokines increases together with a number of attracted immune cells and their cytotoxic activity $[23,24]$.

Tumour necrosis factor $\alpha$ or TNF- $\alpha$ is an important cytokine, which provides proinflammatory and apoptotic stimuli in the context of immune system function. TNF- $\alpha$ acts in the immune response against tumours and viral agents. There is the single-nucleotide polymorphism in the TNF- $\alpha$ encoding gene - SNP rs1800629GA or TNF-308. The presence of the TNF-308 mutation in the TNF gene increases expression levels of its product, cytokine TNF- $\alpha$.

Several studies show opposite results concerning the role of TNF- $\alpha$ rs 1800629 in the natural course and antiviral therapy for chronic hepatitis $C$ [25-27]. The results show the absence of any TNF- $\alpha-308 \mathrm{G} / \mathrm{A}$ influence on the natural course and treatment outcome of chronic hepatitis $\mathrm{C}$ and suggest a modification of HCC development risk [28].

\section{Material and methods}

A group of 130 eligible patients with chronic hepatitis $\mathrm{C}$ were studied in the Hepatology Centre, Minsk City Clinical Hospital of Infectious Diseases, Belarus. The diagnosis of chronic hepatitis $\mathrm{C}$ was defined by positive anti-HCV and detectable HCV RNA (ribonucleic acid) in serum for more than six months. The patients in this study were selected according to the following criteria: age between 18 and 65 years, 1 genotype of $\mathrm{HCV}$, no contraindications for interferon- 
based therapy, negative HBsAg, and absence of cirrhosis. This study included patients with only 1 genotype of HCV because of its high prevalence in Belarus, and because there are the well-known host genetic factors that affect the outcomes of interferon-based treatment in patients with HCV 1 genotype (mainly IL28B). Patients were excluded if there was treatment discontinuation or interruption due to severe side effects, comorbid liver disease, malignancy, HIV coinfection, liver transplantation, or immunosuppressive therapy. The evaluation of fibrosis was made with transient elastography. In addition, the patients with clinical and other paraclinical signs of the portal hypertension were excluded.

\section{Ethical approval}

All procedures performed in studies involving human participants were in accordance with the ethical standards of the institutional and national research committee and with the 1975 Helsinki declaration and its later amendments or comparable ethical standards.

\section{Informed consent}

This was obtained from all participants included in the study.

\section{Treatment protocol}

Each patient received a subcutaneous injection of PEG-IFN (pegylated interferon $a-2 a / a-2 b$ ) once per week or short IFN- $\alpha-2 a$ (interferon $\alpha-2 a$ ) three times a week. The dose of PEG-IFN $\alpha$-2a was $180 \mu$ g together with oral RBV $(1000 \mathrm{mg} /$ day for patients $<75 \mathrm{~kg}$ in weight and $1200 \mathrm{mg} /$ day for patients $\geq 75 \mathrm{~kg}$ in weight). The dose of PEG-IFN- $\alpha-2 b$ was $1.5 \mu \mathrm{g} / \mathrm{kg}$ body weight together with oral RBV $(800 \mathrm{mg} /$ day for patients $<65 \mathrm{~kg}$; $1000 \mathrm{mg} /$ day for patients $>65 \mathrm{~kg}$ and $\leq 80 \mathrm{~kg} ; 1200 \mathrm{mg} /$ day for patients $>85 \mathrm{~kg}$ and $\leq 105 \mathrm{~kg} ; 1400 \mathrm{mg} /$ day for patients $>105 \mathrm{~kg})$. The dose of IFN- $\alpha-2 \mathrm{a}$ was $3,000,000$ ME with oral RBV $(1000 \mathrm{mg} /$ day for patients $<75 \mathrm{~kg}$ in weight and $1200 \mathrm{mg} /$ day for patients $\geq 75 \mathrm{~kg}$ in weight. Quantitative HCV RNA in patients was assessed by using PCR (polymerase chain reaction) at baseline, at week 12, 24, and 48, and 24 weeks after treatment cessation. Sustained virological response (SVR) was considered a positive treatment outcome, defined as undetectable HCV RNA six months after the end of treatment. End of treatment response (EOTR) was defined as undetectable HCV RNA at the end of week 48. Relapse was defined as undetectable HCV RNA at the end of treatment but detectable HCV RNA within 24 weeks of completing treatment. Null virological response (NVR) was defined as less than a two log drop in HCV RNA level by week 12 of treatment. Viral breakthrough was defined as undetectable HCV RNA during treatment followed by detectable HCV RNA during treatment.

\section{HCV detection, quantitative analysis, and genotyping}

Qualitative and quantitative analysis of HCV RNA were performed with RealBest RNA HCV commercial PCR kit (Russian Federation) and Rotor-gene 6000, Corbett Research (Australia). The specificity of the PCR kit included HCV 1a, 1b, 2a, 2b, 2c, 2i, 3, 4, 5a, and 6 genotypes with an RNA detection limit of $>15 \mathrm{ME} / \mathrm{ml}$. The linear range was from $10^{2} \mathrm{ME} / \mathrm{ml}$ to $10^{8} \mathrm{ME} / \mathrm{ml}$. Genotyping of $\mathrm{HCV}$ was performed with a commercial kit RealBest RNA HCV-genotype 1/2/3 (Russian Federation). The specificity of the genotyping kit included HCV 1a, 1b, 2a, 2b, 2c, 2i, 3, 4, 5a, and 6 genotypes, and the sensitivity threshold was $>400 \mathrm{ME} / \mathrm{ml}$.

\section{DNA collection and extraction}

Genetic features of the patients were evaluated in the Institute of Genetics and Cytology of the National Academy of Science, Belarus. Genetic sampling from the buccal epithelium was carried out for the study. The buccal epithelium was taken from an internal cheek surface mucosa smear with a cotton swab. DNA (deoxyribonucleic acid) purification from the buccal scrape (phenol-chloroform extraction), PCR, endonuclease restriction, agarose, and polyacrylamide gel electrophoresis were conducted. To determine genomic variants in the SNPs (single nucleotide polymorphisms) of IL28B (Interleukin 28B), TNF-a (tumour necrosis factor alpha), and CCL5 (Chemokine (C-C motif) ligand 5) genes, all samples were genotyped using PCR-RFLP (polymerase chain reaction - restriction fragment length polymorphism) analysis.

\section{IL28B genotyping}

The PCR was performed in $15 \mu$ reaction mixture containing 1xPCR buffer, $0.25 \mathrm{mM}$ of each dNTP, $0.4 \mu \mathrm{M}$ of each primer, $1.3 \mathrm{mM}$ of $\mathrm{MgCl}_{2}$, and $1.05 \mathrm{U}$ of Taq DNA polymerase. The thermal cycling conditions were: denaturation at $95^{\circ} \mathrm{C}$ for four minutes, subsequently 36 cycles of denaturation at $95^{\circ} \mathrm{C}$ for 30 seconds annealing at $60^{\circ} \mathrm{C}$ for 20 seconds and extension at $72^{\circ} \mathrm{C}$ for 30 seconds. This was followed by the final extension step at $72^{\circ} \mathrm{C}$ for three minutes. The amplified product size was $238 \mathrm{bp}$. The PCR 
products were digested with endonuclease Bsh1236I (BstUI) for 16 hours at $37^{\circ} \mathrm{C}$, resolved on $8 \%$ polyacrylamide gel, and analysed. For samples with ' $\mathrm{C}$ ' allele in the polymorphic site 136, 77 and 25 bp bands were detected, while those with ' $\mathrm{T}$ ' allele had 161 and 77 bp bands.

\section{TNF- $\alpha-308 \mathrm{G} / \mathrm{A}$ genotyping}

Each $15 \mu \mathrm{PCR}$ reaction comprised $1.05 \mathrm{U}$ of Taq DNA polymerase, $1 \times$ PCR buffer, $0.25 \mathrm{mM}$ of each dNTP, $0.5 \mu \mathrm{M}$ of each primer, and $1.5 \mathrm{mM}$ of $\mathrm{MgCl}_{2}$. An initial incubation step of four minutes at $95^{\circ} \mathrm{C}$ was followed by 31 three-step amplification cycles of 30 seconds at $95^{\circ} \mathrm{C}$ for denaturation, 40 seconds at $58^{\circ} \mathrm{C}$ for annealing, 40 seconds at $72^{\circ} \mathrm{C}$ for extension, and a final five-minute extension at $72^{\circ} \mathrm{C}$. The amplified product size was $108 \mathrm{bp}$. Restriction digestion was carried out in $15 \mu \mathrm{l}$ volume in the presence of $1.5 \mathrm{U}$ NcoI endonuclease. The restriction mixture was incubated for 16 hours at $37^{\circ} \mathrm{C}$. The restricted fragments were detected in $8 \%$ polyacrylamide gel. The presence of the 'A' allele was indicated by the presence of 86 and 22 bp fragments, whereas the ' $G$ ' allele resulted in a 108 bp fragment.

\section{CCL5 -403G/A genotyping}

DNA was amplified in a $15 \mu \mathrm{l}$ reaction mixture containing $1.05 \mathrm{U}$ of Taq DNA polymerase, $1 \times$ PCR buffer, $0.25 \mathrm{mM}$ of each dNTP, $0.5 \mu \mathrm{M}$ of each primer, and $1.5 \mathrm{mM} \mathrm{MgCl}_{2}$. PCR was carried out under the following thermal cycling conditions: stage $1-95^{\circ} \mathrm{C}$ for five minutes; stage $2-95^{\circ} \mathrm{C}$ for 20 seconds, $60^{\circ} \mathrm{C}$ for $20 \mathrm{sec}$ onds, and $72^{\circ} \mathrm{C}$ for 20 seconds, for a total of 35 cycles; stage $3-72^{\circ} \mathrm{C}$ for three minutes. The amplified product size was $188 \mathrm{bp}$. The restriction mixture contained $1 \mathrm{U}$ of MnlI endonuclease and the corresponding buffer up to $15 \mu \mathrm{l}$ per probe. The PCR products were incubated for 16 hours at $37^{\circ} \mathrm{C}$. The restricted fragments were detected in $8 \%$ polyacrylamide gel. The presence of the ' $\mathrm{A}$ ' allele was indicated by the presence of a $148 \mathrm{bp}$ fragment, whereas the ' $G$ ' allele resulted in a 139 bp fragment.

\section{Statistical analysis}

The Hardy-Weinberg equilibrium was assessed by a $\chi^{2}$ test with $1 \mathrm{df}$. For univariate analysis, categorical variables were compared by Fisher-Freeman-Halton exact test, the difference between groups in age was compared using Mann-Whitney test. Estimation of interactions between the studied SNPs (IL28B and CCL5) influencing the response was performed by odds ratio and Breslow-Day test for homogeneity of the odds ratio.

Logistic regression modelling was used to establish the importance of the predictors for each dependent variable (EOTR and non-EOTR; SVR and relapse). Odds ratios (ORs) with 95\% confidence intervals (CIs) were calculated for predictors. Paired relative importance of predictors was estimated as the ratio of the two corresponding standardised coefficients [17].

$P$-values $<0.05$ were considered statistically significant.

Analyses were conducted using $\mathrm{R}$ version 3.3 .0 software (R Project for Statistical Computing, http://www. r-project.org).

\section{Results}

Among the studied population with chronic hepatitis C 1 genotype $72(55.4 \%)$ patients were female and $58(44.6 \%)$ patients were male. The mean age of the 130 patients was 39.5 years. Of the 130 patients CC/CT/TT genotypes of IL28B rs12979860 were found in $27(20.8 \%), 74(56.9 \%)$, and $29(22.3 \%)$ patients, respectively. PEG-IFN and short IFN were used in 92 (70.8\%) and 38 (29.2\%) patients, respectively. The proportion of C and T alleles of IL28B rs12979860 was $49.23 \%$ and $50.77 \%$. Hardy-Weinberg equilibrium showed a $p$-value of 0.1137 for IL28B rs12979860. Genotypes GG/GA/AA of -308G/A TNF- $\alpha$ SNP were revealed in $98(75.4 \%), 30(23.1 \%)$ and $2(1.5 \%)$ patients. The frequencies of $\mathrm{G}$ and A alleles of -308G/A TNFa amounted to $86.9 \%$ and $13.1 \%$, respectively. HardyWeinberg equilibrium showed a $p$-value of 0.8633 for -308G/A TNF-a. Genotypes GG/GA/AA of $-403 \mathrm{G} / \mathrm{A}$ CCL5 SNP were revealed in $86(66.2 \%), 39(30 \%)$, and $5(3.8 \%)$ patients, respectively. The frequencies of $\mathrm{G}$ and A alleles of $-403 \mathrm{G} / \mathrm{A}$ CCL5 SNP amounted to $81.15 \%$ and $18.85 \%$, respectively. Hardy-Weinberg equilibrium showed a $p$-value of 0.8263 for $-403 \mathrm{G} / \mathrm{A}$ CCL5. Due to their small number, patients with genotype AA -308G/A TNF- $\alpha$ and genotype AA -403G/A CCL5 were combined for statistical analysis with carriers of GA -308G/A TNF- $\alpha$ (AA + GA -308G/A TNF- $\alpha$ ) and GA -403G/A CCL5 (AA + GA -403G/A CCL5), respectively.

Table 1 presents baseline characteristics of 130 patients according to the therapy results (after 48 weeks).

The analysis revealed a statistically significant difference between frequencies of the IL28B genotypes and IFN type in patients with the end of treatment response and treatment failure $(p<0.001)$.

We obtained heterogeneity in the interaction of IL28B and CCL5 influencing EOTR $(p<0.001)$. Evalu- 
Table 1. Baseline characteristics of 130 patients after 48 weeks of treatment

\begin{tabular}{|c|c|c|c|}
\hline Factor & $\begin{array}{c}\text { End } \\
\text { of treatment } \\
\text { response, } \\
n=65(50 \%)\end{array}$ & $\begin{array}{l}\text { Non-EOTR (null response, } \\
\text { partial response, } \\
\text { breakthrough), } \\
n=65(50 \%)\end{array}$ & $p$ \\
\hline Age (years) & & & 0.560 \\
\hline Range & $21-64$ & $20-63$ & \\
\hline Mean \pm SD & $39.2 \pm 12.8$ & $39.7 \pm 10.1$ & \\
\hline Sex, $n(\%)$ & & & 0.022 \\
\hline Female & $43(66)$ & $29(45)$ & \\
\hline Male & $22(34)$ & $36(55)$ & \\
\hline IFN type, $n(\%)$ & & & $<0.001$ \\
\hline IFN & $9(14)$ & $29(45)$ & \\
\hline PEG-IFN & $56(86)$ & $36(55)$ & \\
\hline IL28B, n (\%) & & & $<0.001$ \\
\hline $\mathrm{CC}$ & $24(37)$ & $3(5)$ & \\
\hline $\mathrm{CT}$ & $31(48)$ & $43(66)$ & \\
\hline$\Pi$ & $10(15)$ & $19(29)$ & \\
\hline TNF- $\alpha, n(\%)$ & & & 0.839 \\
\hline$A A+G A$ & $17(26)$ & $15(23)$ & \\
\hline GG & $48(74)$ & $50(77)$ & \\
\hline CCL5, n (\%) & & & 0.578 \\
\hline $\mathrm{AA}+\mathrm{GA}$ & $24(37)$ & $20(31)$ & \\
\hline GG & $41(63)$ & $45(69)$ & \\
\hline
\end{tabular}

EOTR - end of treatment response, IFN - interferon $\alpha$-2a, PEG-IFN - pegylated interferon $\alpha 2 a / \alpha 2 b$, IL28B - interleukin 28B, TNF- $\alpha$ - tumour necrosis factor alpha, CCL5 - chemokine [C-C motif] ligand 5

ation of interactions between the studied SNPs revealed obvious synergy between IL28B CT and -403G/A CCL5 GG genotypes in the prediction of failure to achieve EOTR (Table 2).

Since an interaction between genotypes IL28B and CCL5 (Table 2) had been established, we carried out modelling using independent variables (sex, IL28B, and CCL5) with and without the interaction of the SNPs. The model with the interaction (Table 3) gave better statistical results compared to the model without the interaction $(p=0.002)$.

The following data from Table 3, using short IFN, decreased the chances for the end of treatment response by a factor of 6.1 (95\% CI: 2.1-21) over PEG-IFN. Male sex decreased the chances for the achievement of the end of treatment response by a factor of 3.7 (95\% CI: 1.5-9.7).

TT IL28B genotype was found to decrease the chances for the end of the treatment response by a factor of 29.0 (95\% CI: 6.4-183) compared with CC IL28B.

CT IL28B genotype together with GA or AA CCL5 genotype decreased the chances of EOTR by a factor of 7.0 (95\% CI: 1.5-160) compared with CC IL28B genotype (independently of CCL5). The combination of CT IL28B and GG CCL5 genotypes decreases the chances for EOTR by a factor of 29 (95\% CI: 6.4183), and TT IL28B genotype independently of CCL5. Genotypes IL28B CT with CCL5 GG had statistically higher relative importance $(p=0.004)$ than genotypes IL28B CT with CCL5 GA or AA, and it did not differ from that of IL28B TT genotype $(p=0.169)$.

Table 4 presents baseline characteristics of patients with relapse or SVR after EOTR.

Multivariate analysis was used to identify the factors affecting the risk of the treatment relapse; -308G/A TNF- $\alpha$ GA or AA genotype increased the risk of relapse by 9.4 times (95\% CI: 2.4-48). In addition, IL28B TT genotype, independently of CCL5 genotype or combination of IL28B CT and CCL5 GG genotypes, increased the risk of relapse by a factor of 7.2 times (95\% CI: 1.9-37) compared with IL28B CC genotype or a combination of IL28B CT and CCL5 GA/AA genotypes (Table 5).

\section{Discussion}

In this study, SVR was observed in $49(37.7 \%)$ of 130 patients.

Prognostic predictors for assessing the risk of non-achieving EOTR and relapse were established. The use of short IFN (OR = 6.1; 95\% CI: 2.1-21), male sex $(\mathrm{OR}=3.7 ; 95 \% \mathrm{CI}: 1.5-9.7)$ were found to decrease the chances for the end of treatment response. IL28B TT genotype also caused a negative effect, decreasing EOTR rates by a factor of 29.0 (95\% CI: 6.4-183). Apparently, these results reveal the crucial role of IL28B

Table 2. Interactions between SNPs affecting EOTR

\begin{tabular}{lcccccc}
\hline & \multicolumn{2}{c}{ IL28B CC, $\boldsymbol{n}=\mathbf{2 7}$} & \multicolumn{2}{c}{ IL28B CT, $\boldsymbol{n}=\mathbf{7 4}$} & \multicolumn{2}{c}{ IL28B $\Pi, \boldsymbol{n}=\mathbf{2 9}$} \\
\cline { 2 - 7 } & EOTR & Non-EOTR & EOTR & Non-EOTR & EOTR & Non-EOTR \\
\hline CCL5 AA + GA & $7(29)$ & $3(100)$ & $15(48)$ & $7(16)$ & $2(20)$ & $10(53)$ \\
\hline CCL5 GG & $17(71)$ & 0 & $16(52)$ & $36(84)$ & $8(80)$ & $9(47)$ \\
\hline Odds ratio & \multicolumn{3}{c}{$0(0-1.3)$} & \multicolumn{2}{c}{$4.7(1.6-14.1)$} & $0.2(0-1.4)$ \\
\hline
\end{tabular}

SNP - single nucleotide polymorphism, EOTR - end of treatment response, IL28B - interleukin 28B, CCL5 - chemokine [C-C motif] ligand 5 
Table 3. Multivariate analysis of response (non-EOTR vs. EOTR)

\begin{tabular}{|c|c|c|c|}
\hline Factor & Odds ratio & $\begin{array}{l}95 \% \text { confidence } \\
\text { interval }\end{array}$ & $p$ \\
\hline Treatment & & & 0.002 \\
\hline PEG-IFN & Reference & & \\
\hline IFN & 6.1 & $2.1-21$ & \\
\hline Sex & & & 0.006 \\
\hline Female & Reference & & \\
\hline Male & 3.7 & $1.5-9.7$ & \\
\hline \multicolumn{4}{|l|}{ IL28B } \\
\hline $\mathrm{CC}$ & Reference & & \\
\hline $\mathrm{CT}$ with $\mathrm{CCL} 5$ (GA or $\mathrm{AA})$ & 7.0 & $1.5-160$ & 0.022 \\
\hline CT with CCL5 (GG) & 28.5 & $7.2-160$ & $<0.001$ \\
\hline$\Pi$ & 29.0 & $6.4-183$ & $<0.001$ \\
\hline
\end{tabular}

EOTR - end of treatment response, PEG-IFN - pegylated interferon $\alpha 2 a / \alpha 2 b$, IFN - interferon a2a, IL28B - interleukin 28B, CCL5 - chemokine [C-C motif] ligand 5

in efficacy prediction of interferon-based treatment for chronic hepatitis $\mathrm{C} 1$ genotype.

Analysis of the interaction between genetic predictors revealed that CCL5 GG and IL28B CT decreased the chances of EOTR when presented simultaneously. Patients with combinations of these genotypes had increased risk of failure to achieve EOTR by a factor of 28.5 (95\% CI: 7.2-160). Furthermore, the combination of CCL5 GG and IL28B CT contributed to treatment failure risk at the same level as IL28B TT.

Patients with chronic hepatitis $\mathrm{C}$, who achieve EOTR due to interferon-based treatment, may benefit from using TNF- $\alpha$ (-308) G/A SNP as an independent predictor of relapse. Genotypes GA and AA of TNF- $a$ $(-308)$ G/A SNP were found to significantly increase the risk of relapse in patients who achieved the end of treatment response $(\mathrm{OR}=9.4 ; 95 \% \mathrm{CI}: 2.4-48)$.

\section{Conclusions}

The effect of the well-known predictor IL28B was also observed in this study. Two SNPs (CCL5 and TNF- $\alpha$ [-308] G/A) were found to increase the quality of prediction by IL28B in patients with chronic hepatitis C 1 genotype. These results may provide benefits for practitioners, particularly when deciding on a treatment regimen. However, novel additional predictors require further investigation and verification on larger numbers of patients.

\section{Acknowledgments}

We would like to thank our colleagues Aleg Liaudanski, Ph.D. in Biological Sciences, Maksim Rodzkin,
Table 4. Baseline characteristics of 65 patients with EOTR in accordance with achieving relapse or SVR

\begin{tabular}{lccc}
\hline Factor & $\begin{array}{c}\text { SVR, } n=49 \\
(75 \%)\end{array}$ & $\begin{array}{c}\text { Relapse, } n=16 \\
(25 \%)\end{array}$ & $p$ \\
\hline Age (years) & & 0.175 \\
\hline Range & $21-64$ & $20-63$ & \\
\hline Mean \pm SD & $38.1 \pm 12.7$ & $42.8 \pm 12.8$ & \\
\hline Sex, $n$ (\%) & & & $>0.99$ \\
\hline Female & $32(65)$ & $11(69)$ & \\
\hline Male & $17(35)$ & $5(31)$ & \\
\hline IFN type, $n(\%)$ & & & 0.284 \\
\hline IFN & $5(10)$ & $4(25)$ & \\
\hline PEG-IFN & $44(90)$ & $12(75)$ & \\
\hline IL28B, $n$ (\%) & & & \\
\hline CC & $22(45)$ & $2(12)$ & \\
\hline CT with CCL5 & $12(25)$ & $3(19)$ & \\
\hline GA + AA) & & & \\
\hline CT with CCL5 (GG) & $11(22)$ & $5(31)$ & \\
\hline$\pi$ & $4(8)$ & $6(38)$ & \\
\hline TNF- $\alpha, n(\%)$ & & & \\
\hline AA + GA & $8(16)$ & $9(56)$ & \\
\hline GG & $41(84)$ & $74)$ & \\
\hline
\end{tabular}

EOTR - end of treatment response, SVR - sustained virological response, IFN - interferon $\alpha 2 a$, PEG-IFN - pegylated interferon $\alpha 2 a / \alpha 2 b$, IL28B - interleukin 28B,

CCL5 - chemokine [C-C motif] ligand 5, TNF-a - tumour necrosis factor alpha

Table 5. Multivariate analysis of factors affecting relapse rates

\begin{tabular}{lccc}
\hline Factor & Odds ratio & $\begin{array}{c}95 \% \\
\text { confidence } \\
\text { interval }\end{array}$ & $p$ \\
\hline TNF $\alpha$ & \multicolumn{3}{c}{0.003} \\
\hline GG & Reference & \\
\hline AA + GA & 9.4 & $2.4-48$ & \\
\hline Unfavourable gene combination & & & \\
\hline $\begin{array}{l}\text { IL28B CC or CT with CCL5 } \\
\text { (GA or AA) }\end{array}$ & Reference & & \\
\hline IL28B T or CT with CCL5 (GG) & 7.2 & $1.9-37$ & 0.008 \\
\hline
\end{tabular}

TNF-a - tumour necrosis factor alpha, IL28B - interleukin 28B, CCL5 - chemokine [C-C motif] ligand 5

Oleg Davydenko, Ph.D. in Biological Sciences, D.Sc. from Institute of Genetics and Cytology of the National Academy of Sciences of Belarus, who provided comprehensive assistance and expertise with the genetic part of this research.

\section{Disclosure}

Authors report no conflict of interest. 


\section{References}

1. Messina JP, Humphreys I, Flaxman A, et al. Global distribution and prevalence of hepatitis C virus genotypes. Hepatology 2015; 61: 77-87.

2. McCaughan GW. Fibrosis progression in chronic hepatitis C virus infection. Gut 2004; 53: 318-321.

3. Lingala S, Ghany MG. Natural History of Hepatitis C. Gastroenterol Clin North Am 2015; 44: 717-734.

4. Thein HH, Yi Q, Dore GJ, et al. Estimation of stage-specific fibrosis progression rates in chronic hepatitis $\mathrm{C}$ virus infection: A meta-analysis and meta-regression. Hepatology 2008; 48: 418431.

5. Curry MP. HIV and Hepatitis C Virus: Special Concerns for Patients with Cirrhosis. J Infect Dis 2013; 207 (Suppl 1): S40-44.

6. Fattovich G, Giustina G, Degos F, et al. Morbidity and mortality in compensated cirrhosis type C: A retrospective follow-up study of 384 patients. Gastroenterology 1997; 112: 463-472.

7. Lozano R, Naghavi M, Foreman K, et al. Global and regional mortality from 235 causes of death for 20 age groups in 1990 and 2010: a systematic analysis for the Global Burden of Disease Study 2010. Lancet 2012; 380: 2095-2128.

8. Smith DB, Bukh J, Kuiken C, et al. Expanded classification of hepatitis $C$ virus into 7 genotypes and 67 subtypes: updated criteria and genotype assignment web resource. Hepatology 2014; 59: 318-327.

9. Murphy DG, Sablon E, Chamberland J, et al. Hepatitis C Virus Genotype 7, a New Genotype Originating from Central Africa. Loeffelholz MJ, editor. J Clin Microbiol 2015; 53: 967-972.

10. EASL Recommendations on Treatment of Hepatitis C 2015. J Hepatol 2015; 63: 199-236.

11. Buckton AJ, Ngui SL, Arnold C, et al. Multitypic Hepatitis C Virus Infection Identified by Real-Time Nucleotide Sequencing of Minority Genotypes. J Clin Microbiol 2006; 44: 2779-2784.

12. Cunningham EB, Applegate TL, Lloyd AR, et al. Mixed HCV infection and reinfection in people who inject drugs - impact on therapy. Nat Rev Gastroenterol Hepatol 2015; 12: 218-230.

13. Razavi $\mathrm{H}$, ElKhoury AC, Elbasha E, et al. Chronic hepatitis $\mathrm{C}$ virus (HCV) disease burden and cost in the United States. Hepatology 2013; 57: 2164-2170.

14. McHutchison JG, Lawitz EJ, Shiffman ML, et al. Peginterferon Alfa-2b or Alfa-2a with Ribavirin for Treatment of Hepatitis C Infection. N Engl J Med 2009; 361: 580-593.

15. Manns MP, McHutchison JG, Gordon SC, et al. Peginterferon alfa- $2 \mathrm{~b}$ plus ribavirin compared with interferon alfa- $2 \mathrm{~b}$ plus ribavirin for initial treatment of chronic hepatitis $\mathrm{C}$ : a randomised trial. Lancet 2001; 358: 958-965.

16. Hauser G, Awad T, Brok J, et al. Peginterferon plus ribavirin versus interferon plus ribavirin for chronic hepatitis $\mathrm{C}$. In: The Cochrane Collaboration, editor. Cochrane Database of Systematic Reviews [Internet]. Chichester, UK: John Wiley \& Sons, Ltd; 2014 [cited 2016 Feb 25]. Available from: http://doi.wiley. com/10.1002/14651858.CD005441.pub3

17. Silber JH, Rosenbaum PR, Ross RN. Comparing the Contributions of Groups of Predictors: Which Outcomes Vary with Hospital Rather Than Patient Characteristics. J Am Statist Assoc 1995; 90: 7.

18. Ge D, Fellay J, Thompson AJ, Simon JS, et al. Genetic variation in IL28B predicts hepatitis $\mathrm{C}$ treatment-induced viral clearance. Nature 2009; 461: 399-401.

19. Tanaka Y, Nishida N, Sugiyama M, et al. Genome-wide association of IL28B with response to pegylated interferon- $\alpha$ and ribavirin therapy for chronic hepatitis C. Nat Genet 2009; 41: 1105-1109.
20. Sarrazin C, Susser S, Doehring A, et al. Importance of IL28B gene polymorphisms in hepatitis $C$ virus genotype 2 and 3 infected patients. J Hepatol 2011; 54: 415-421.

21. Lange CM, Moradpour D, Doehring A, et al. Impact of donor and recipient IL28B rs12979860 genotypes on hepatitis C virus liver graft reinfection. J Hepatol 2011; 55: 322-327.

22. Katsounas A, Schlaak JF, Lempicki RA. CCL5: A Double-Edged Sword in Host Defense Against the Hepatitis C Virus. Int Rev Immunol 2011; 30: 366-378.

23. Kusano F, Tanaka Y, Marumo F, et al. Expression of C-C chemokines is associated with portal and periportal inflammation in the liver of patients with chronic hepatitis C. Lab Invest 2000; 80: 415-422.

24. Shields PL, Morland CM, Salmon M, et al. Chemokine and chemokine receptor interactions provide a mechanism for selective $\mathrm{T}$ cell recruitment to specific liver compartments within hepatitis C-infected liver. J Immunol 1999; 163: 6236-6243.

25. Grandi T, Silva CMD da, Amaral KM, et al. Tumour necrosis factor -308 and -238 promoter polymorphisms are predictors of a null virological response in the treatment of Brazilian hepatitis $C$ patients. Memórias do Instituto Oswaldo Cruz 2014; 109: 345-351.

26. Zhang X, Hu D, Zhu B, et al. Tumor Necrosis Factor- $\alpha$ Promoter Gene Polymorphisms Are Not Associated with Hepatitis C Virus Infection in Chinese Hemodialysis Patients. Ren Fail 2011; 33: 593-599.

27. He J, Pei X, Xu W, et al. The Relationship between Tumor Necrosis Factor- $\alpha$ Polymorphisms and Hepatitis C Virus Infection: A Systematic Review and Meta-Analysis. Ren Fail 2011; 33: 915922.

28. Talaat RM, Esmail AA, Elwakil R, et al. Tumor necrosis factor-alpha $-308 \mathrm{G} / \mathrm{A}$ polymorphism and risk of hepatocellular carcinoma in hepatitis C virus-infected patients. Chin J Cancer 2012; 31: 29-35 